medical superintendents and their successors, the unit medical officers, working at hospital level in Scotland, whose duties were and are closely similar to those he specified. The terminology of "contract negotiation" and "outcome review" may be new; but these processes are not so very different from endeavours to specify the pattern of provision of services and to assess their effectiveness, which were in operation long before the introduction of general management. Admittedly, the former medical administrators were officers, rather than executive directors, of their boards, but any suggestion that this must have allowed them a lesser degree of executive authority than will be enjoyed by the medical director could be offered only by those too young to have encountered a senior administrative medical officer or a group medical superintendent.

I take issue with $\mathrm{Mr}$ Johnston's assertion that the training for consultants in public health medicine is not in the main appropriate for medical directors. One of the initial purposes of the (then) Faculty of Community Medicine on its creation in 1972 was to establish a programme of structured training not only for hospital medical administrators but also for their colleagues in local authority public health services, the civil service, and academic departments. It was accepted that "a common basic training" was necessary for a diverse range of medical administrative work, described in detail in the Hunter report. ${ }^{2}$ If it were accepted, $\mathrm{Mr}$ Johnston's perception that this training is not appropriate for the medical director would constitute a grave criticism of the educational objectives and achievements of the faculty during the past two decades, as well as a sad reflection on the working relationships between clinical consultants and public health physicians.

Unfortunately, the recent and impending changes in the NHS have induced in many public health physicians a greater concern for broader epidemiological issues, including "needs assessment," communicable disease control, and health promotion, than for immediate involvement in such operational issues as the management and development of specialist services. This leads them to believe that most of their future professional work must rest at the level of the purchasing agencies rather than the provider units. $\mathrm{Mr}$ Johnston presents cogent reasons for a reappraisal of this view. It is to be hoped that managers in the new provider units may be persuaded of the sense of his general arguments and that a sufficient number of public health physicians will commit their careers to the provider units, grasping the opportunity to ensure provision of effective medical administration in all hospitals throughout the country.

DAVID MORRIS

Division of Epidemiology and Public Health,

University of Newcastle upon Tyne,

Newcastle upon Tyne NE2 +HH

1 Johnston IH. What will the medical director do? B.MF 1991;302 280-1. (2 February.)

2 Department of Health and Social Security. Report of the working party on medicai administrators. London: HMSO, 1972 (Hunter report.)

\section{Discontinuing ACE inhibition in patients with diabetic nephropathy}

SIR,-The Melbourne Diabetic Nephropathy Study Group has recently reported that stopping 12 months' treatment with perindopril or nifedipine in hypertensive and normotensive diabetic patients with microalbuminuria was associated with a sustained increase in albuminuria and mean blood pressure, and it concluded that in these patients blood pressure seems to be an important determinant of urinary albumin excretion. '
In 12 diabetic patients recruited in a trial to investigate the effects of the angiotensin converting enzyme inhibitor benazepril on albuminuria and blood pressure we stopped treatment with $20 \mathrm{mg}$ enalapril once daily after a mean duration of 36 (range 6-74) months. Seven patients were insulin dependent and five non-insulin dependent, and all had diabetic retinopathy. As shown in the table, mean arterial pressure and albuminuria that had been decreased by enalapril subsequently increased after one month and two months of treatment with placebo and decreased in all patients after three months of treatment with benazepril. The changes in albuminuria were parallel to the changes in blood pressure.

Effect of stopping treatment with enalapril and subsequent treatment with benazepril in 12 patients with diabetic nephropathy

\begin{tabular}{|c|c|c|}
\hline & $\begin{array}{c}\text { Mean }(\mathrm{SE}) \\
\text { arterial pressure } \\
(\mathrm{mm} \mathrm{Hg})\end{array}$ & $\begin{array}{c}\text { Median (range) } \\
\text { albumin excretion rate } \\
(\mathrm{mg} / 24 \mathrm{~h})\end{array}$ \\
\hline \multirow{5}{*}{$\begin{array}{l}\text { Baseline } \\
\text { During treatment: } \\
\text { With enalapril } \\
\text { With placebo } \\
\text { ( } 1 \text { month) } \\
\text { With placebo } \\
\text { ( } 2 \text { months) } \\
\text { With benazepril } \\
\text { ( } 3 \text { months) }\end{array}$} & $115 \cdot 0(4 \cdot 3)$ & $324(35-1183)$ \\
\hline & $103 \cdot 0(2 \cdot 5)$ & $81(12-265)$ \\
\hline & $114 \cdot 0(3 \cdot 6)$ & $341(71-1145)$ \\
\hline & $112 \cdot 4(2 \cdot 4)$ & $228(24-843)$ \\
\hline & $98 \cdot 9(3 \cdot 3)$ & $159(14-462)$ \\
\hline
\end{tabular}

These results are in keeping with those of the Melbourne group and emphasise the role of blood pressure as a determinant of albuminuria in diabetic nephropathy.

PHILIPPE PASSA HERVÉ LEBLANC ANTOINE CHEVREL

Department of Diabetology,

Hôpital Saint Louis.

75010 Paris, France

JÖ̈L MENARD

Department of Cardiovascular Preventive Medicine,

Hôpital Broussais,

75014 Paris

Melbourne Diabetic Nephropathy Study Group. Comparison between perindopril and nifedipine in hypertensive an normotensive diabetic patients with microalbuminuria. $B M Y$ 1991;302:210-6. (26 January.)

\section{Violence in general practice}

SIR,-Predictably Dr F D Richard Hobbs's paper on aggression against general practitioners ${ }^{1}$ attracted meretricious headlines in the medical press, notably in the Medical Monitor and GP News. ${ }^{23}$

It does not help our understanding of this problem to deal with threats, verbal abuse, and physical violence as if they were part of a continuum. The playground rhyme "Sticks and stones may break my bones; But words can never hurt me" suggests widespread acceptance of a discontinuity between words and action. Threats and verbal abuse (especially in the context of a confidential consultation reported by only one party) are subjective and impossible to measure. Indeed they may be part of an exchange in which the doctor has played a provocative part. Physical contact, on the other hand, is readily categorised and, whatever the provocation, tips the scales of justice irrevocably against the aggressor.

Violence within the doctor-patient relationship is often the result of frustration at unmet expectations meeting frustration at the level of demand. Whether or not the expectations are justified or the level of demand reasonable depends on your point of view, but if there is any dispute the doctor will not be prosecuting counsel, jury, and judge as in Dr Hobbs's investigation.

For more than 10 years I have managed a medical deputising service covering the city of
Dundee. Recently we have done over 10000 visits annually, which is more out of hours calls than a general practitioner does in a lifetime. In all these years only two doctors have been assaulted with injury.

If deputising doctors suffer less aggression than general practitioners the fault may lie with the general practitioners as patients are the same. A locum commented that he saw much more violence in the local casualty department (where he also worked) than when he was deputising, and he confessed that he was far more likely to get angry in the hospital than when visiting a patient's house.

Nevertheless, our figures may not be so different from those of Dr Hobbs. If his report had been restricted to the fact that in over 1000 "general practice years" only 41 doctors were assaulted with injury, and that in 19 of these incidents the patient had a mental illness, the $B M \mathcal{F}$ might not have published it, and it certainly would not have attracted misleading headlines in other publications.

Dundee DD46RB

JOHN HULBERT

1 Hobbs FDR. Violence in general practice: a survey of general practitioners' views. BMF 1991;302:329-32. (9 February.)

Anonymous. West Midlands GPs face frequent aggression. Medical Monitor 1991 Feb 15:11.

Anonymous. GPs are plagued by violent patients. GP News 1991 Feb 15:8.

\section{Coxsackie B virus and postviral fatigue syndrome}

SIR,-Dr N A Miller and colleagues highlight the difficulty of associating a virus (coxsackie B virus) with a disease (postviral fatigue syndrome) when the virus in question is common in the general population.' In a recent serological survey of the family members of children with insulin dependent diabetes mellitus we also found a high prevalence of IgM antibody specific to enterovirus: $14 \%$ of children with recently diagnosed insulin dependent diabetes mellitus, $8 \%$ of unaffected siblings, and $18 \%$ of parents had the antibody at the time of entry into the study. Serum samples were collected between 1985 and 1987. These seroprevalence figures are higher than those reported among control populations in earlier studies in the United Kingdom $-5.5 \%$ in children during $1982^{2}$ and $3.5 \%$ in adults during 1979-80. ${ }^{3}$ Because the assay used in these studies was the same as that used by Dr Miller and colleagues this indicates that enterovirus was endemic during 1985-7, which covers the period of the study of Dr Miller and colleagues.

In patients with acute enterovirus infection, enterovirus specific $\operatorname{Ig} M$ antibody responses usually decline over a period of three to six months. In our study in diabetic families, of 49 individuals positive for antibody from whom follow up samples were available, $43 \%(21)$ had detectable antibody at six months' follow up, but only $6 \%$ (three) had at 12 months' follow up. To show an association between enterovirus infection and chronic disease with serological techniques it is necessary to show not only the presence of enterovirus specific $\operatorname{Ig} M$ antibody but also its persistence. Thus in a recent study in which we provided serological evidence of persistent enterovirus infection in patients with chronic heart disease, ${ }^{4}$ our conclusion was based not only on the presence of antibody in $64 \%$ of patients with chronic relapsing pericarditis and $33 \%$ with dilated cardiomyopathy (compared with $12 \%$ in controls) but also on the persistence of these responses over periods of up to 10 years.

In a recent survey of 100 patients with the postviral fatigue syndrome referred to this laboratory, $31 \%$ had enterovirus specific IgM antibody, a figure similar to that found by Dr Miller and colleagues. We have also followed up 11 patients and found that antibody responses persisted for 